\title{
A COMPARATIVE STUdy AlgORITHM FOR NOISY IMAGE RESTORATION IN THE FIELD OF MEDICAL IMAGING
}

\author{
Dr.P.Sumitra \\ Assistant Professor, Department of Computer Science, Vivekanandha College of Arts and \\ Sciences for Women(Autonomous) \\ Elayampalayam,Tiruchengode
}

\begin{abstract}
This paper presents the performance analysis of different basic techniques used for the image restoration. Restoration is a process by removing blur and noise from image and get back the original form. Medical images play a vital role in dealing with the detection of various diseases in patients and they face the problem of salt and pepper noise and Gausian noise. Hence restoration is performed based on different image restoration techniques. In this paper, popular restoration techniques is applied and analyzed in the recovery of medical images,.
\end{abstract}

\section{KEYWORDS}

Image Restoration, Inverse Filter, Weiner Filter, MSE, PSNR, Medical Images

\section{INTRODUCTION}

Image Processing is a form of signal processing for which the input is an image either it can be photograph or video frame. The output of the image can be set of characteristics or parameters related to the image. It includes several techniques such as image segmentation, image recognition, image restoration, etc[1]. Image Restoration is an up-and-coming field of image processing which refers to group of methods or techniques that focus on recovering an original image from a degraded image. The degradation may occur due to several ways that includes sensor noise, camera misfocus, relative object-camera motion, random atmospheric turbulence [2][3]. There are two subprocesses.

i. Degrading the quality of the image by adding blur and noise to an image

ii. Recovering the original image.

\section{Degradation Model for Blurring Image}

In degradation model for blurring image, the image is blurred using different kinds of filters and an additive noise. The image can be degraded by using salt and pepper noise and Gaussian Noise. The degraded image can be express by the equation as

$$
\mathrm{f}=\mathrm{g} * \mathrm{~h}+\mathrm{n}
$$

where $f$ denotes the observed blurred image $\mathrm{g}$ denotes the clear image to recover 
International Journal of Advanced Information Technology (IJAIT) Vol. 6, No. 1, February 2016

$\mathrm{h}$ denotes the blur kernel

$\mathrm{n}$ denotes the noise

The below Figure 1 represents the formation of degradation model for blurring image.

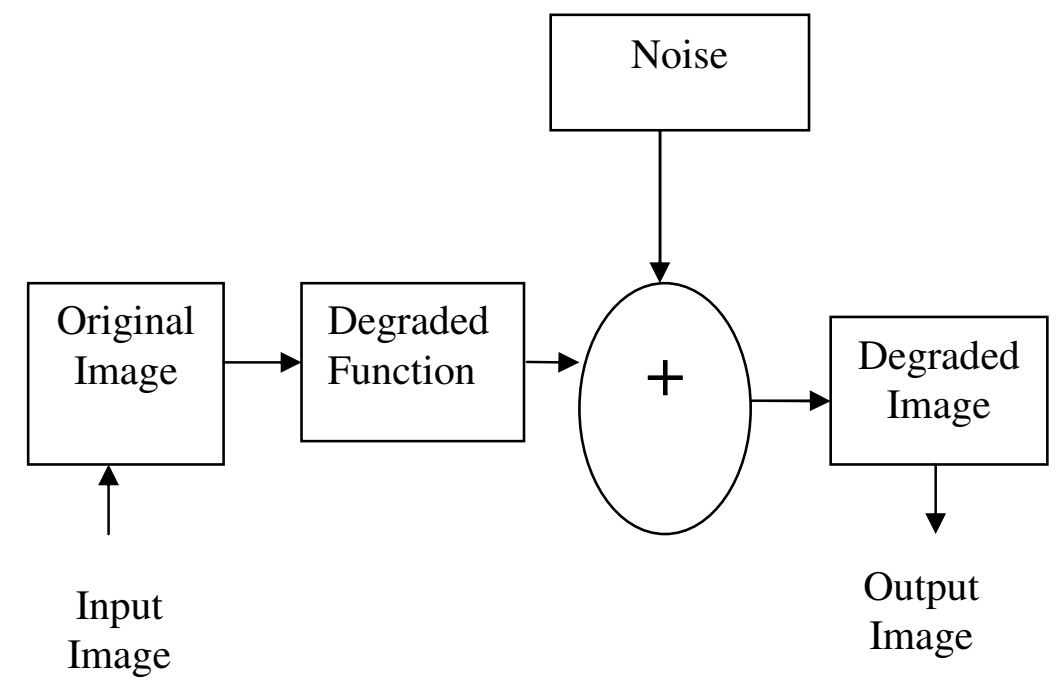

Figure 1. Degradation Model for blurring image

\section{Restoration Model}

Restoration is obtained by degrading the image using restoration filters. In this process, noise and blur image factor is removed and we get the estimated original image. Figure 2 represents the structure of restoration model [4].

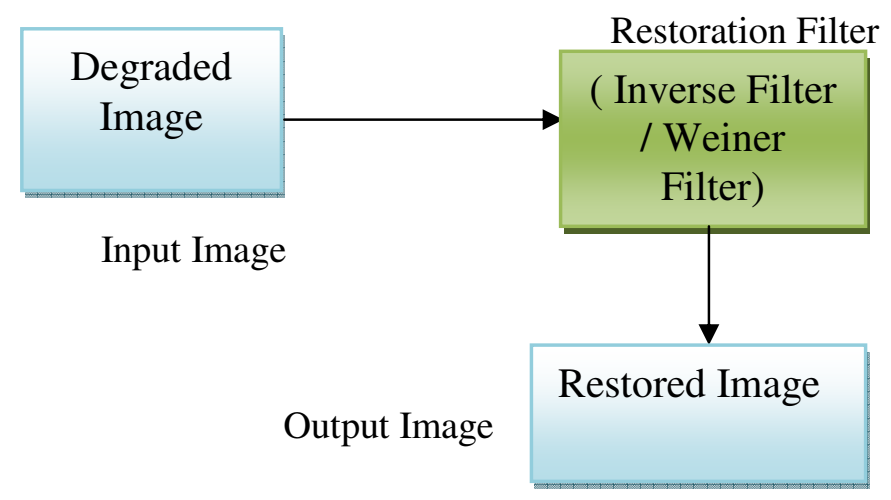

Figure 2: Restoration Model

\section{RESTORATION TECHNIQUES}

The two types of image restoration techniques are

1. Blind Techniques

2. Non-Blind Techniques 


\subsection{Blind Image Restoration}

This method allows the reconstruction of original images from degraded image. The major type applied is Blind Image Deconvolution(BID). It is difficult to implement and more complicated when compared to other category[5]

\subsection{Non-Blind Restoration}

This technique helps in reconstruction of original image from degraded image. The image can be degraded by having the knowledge of PSF. In this paper we are going to consider about Inverse Filtering and Weiner Filtering.

\section{INVERSE FILTERING}

Inverse filtering is the quickest and easiest way to restore the blurred image. Blurring can be considered as low pass filtering in inverse filtering approach we use high pass filtering action to reconstruct the blurred image without much effort.

\section{WEINER FILTERING}

Weiner filtering has been a classical tool in signal processing and communication since the 1950's[6].It is a standard image restoration approach for both the degraded function and statistical characteristic of noise into the restoration function. It is non-blind technique for reconstructing the degraded image which is known as PSF. It removes the additive noise and inverts the blurring simultaneously. Wiener filter not only performs the deconvolution by inverse filtering but also removes the noise with the compression operation. The input to a weiner filter is a degraded image corrupted by additive noise [7]

\section{Medical Image Restoration}

Image restoration techniques are applied to restore images from astronomical field and satellite images [8][9]. In this paper, medical image restoration is mainly focused.

\subsection{Medical Images}

Medical Images are used to detect a number of diseases which cannot be detected anywhere. These images may be contaminated with noise or blur image which feels difficult for the doctor to identify the diseases. This restoration of such degraded images is must for the well being of the common people. There are a number of medical images which are X-ray images, Ultrasound images, CT scan images and MRI images as shown Figure 3. 


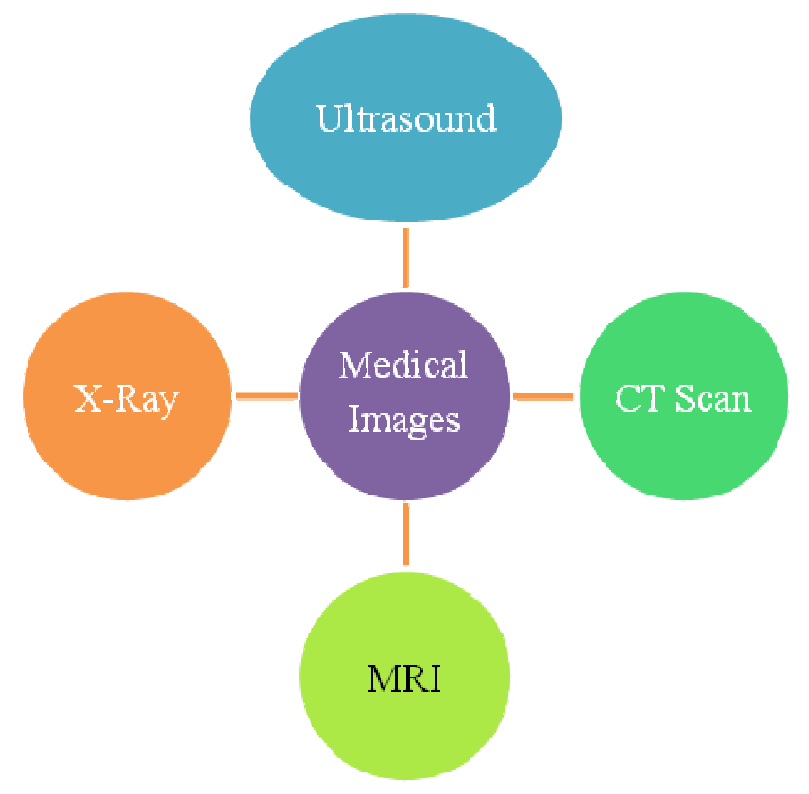

Figure 3: Medical Images

\subsubsection{X-ray images}

It is a popular imaging test that has been used for decades to help doctors view the inside of the body without having to make an incision. It is used to find orthopaedic damage, tumours, pneumonias, etc.

\subsubsection{Ultrasound images}

Ultrasound image uses high-frequency sound waves to view inside the body. Ultrasound are captured in real-time, they can also show movement of the body's internal organs as well as blood flowing through the blood vessels. It is a medical tool that can help a physician evaluate, diagnose and treat medical conditions.

\subsubsection{CT Scan images}

Computed tomography $(\mathrm{CT})$ is a noninvasive medical examination that uses specialized $\mathrm{X}$-ray equipment to produce cross-sectional images of the body. CT scans can be performed on every region of the body for a variety of reasons (e.g., diagnostic, treatment planning, interventional, or screening). Most CT scans are performed as outpatient procedures.

\subsubsection{MRI images}

Magnetic resonance imaging(MRI) is a medical imaging procedure that uses strong magnetic fields and radio waves to produce cross-sectional images of organs and internal structures in the body. Using MRI scans, physicians can diagnose or monitor treatments for a variety of medical conditions which includes tumors, heart problems, diseases of the liver etc. 
International Journal of Advanced Information Technology (IJAIT) Vol. 6, No. 1, February 2016

\section{RESULTS FOR DEBLURRED IMAGES}

The proposed approach is experimented using a test image X-ray, CT, MRI,and Ultrasound image of size 256x256 as shown in Figure 5,Figure 6, Figure 7 and Figure 8 with different noise type.

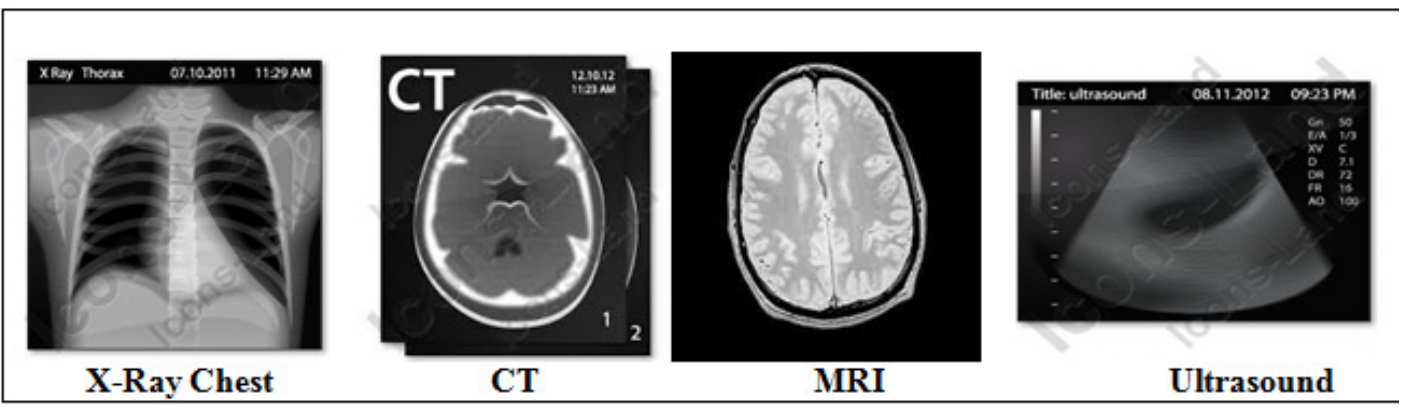

Figure 5. Original Image of Medical Imaging of Size 256 x 256

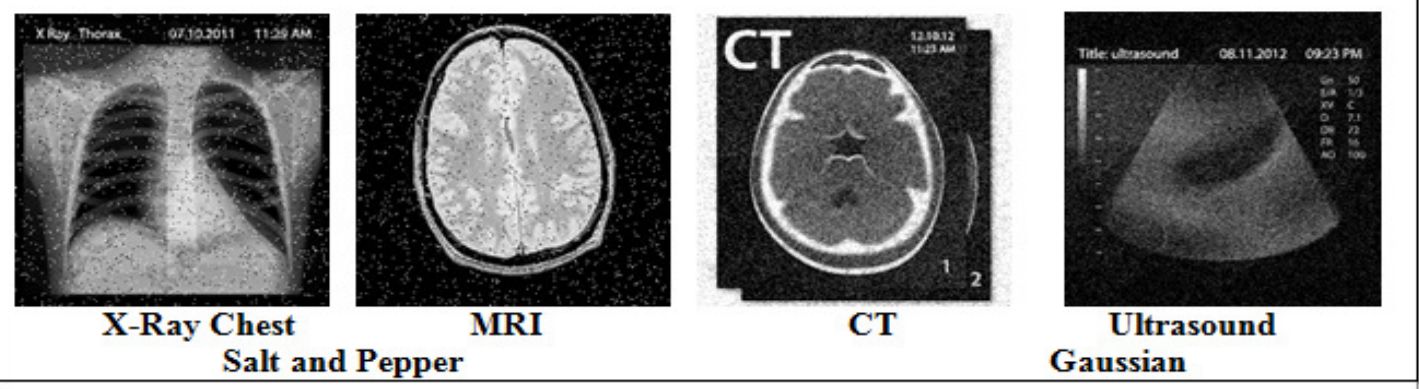

Figure 6. Degraded Image of Medical Imaging of Size 256 x 256 with different Noise types

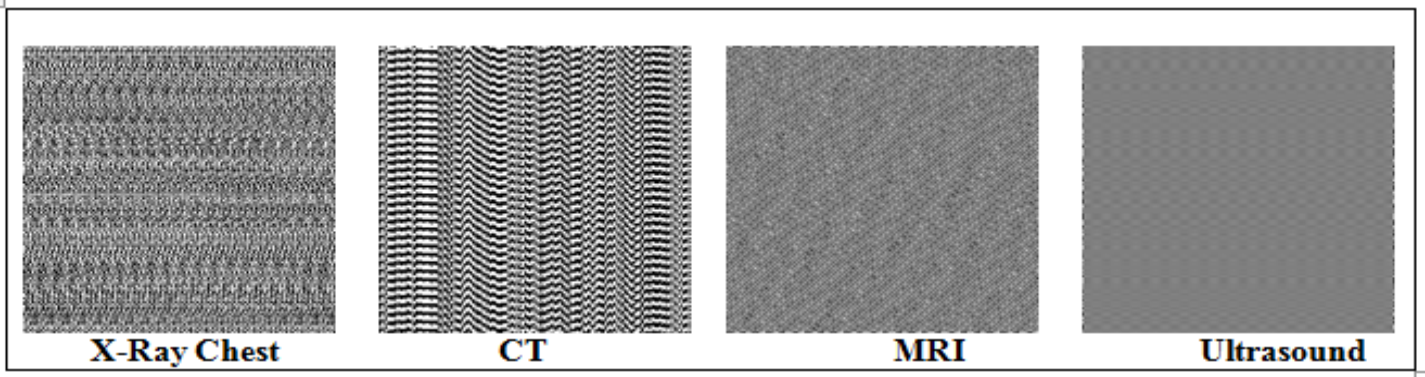

Figure 7. Restored image of X-Ray Chest, CT, MRI and Ultrasound using Inverse Filter

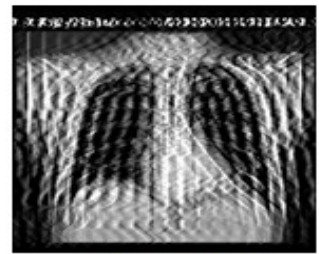

X-Ray Chest

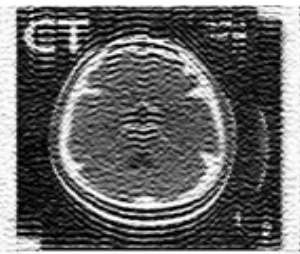

CT

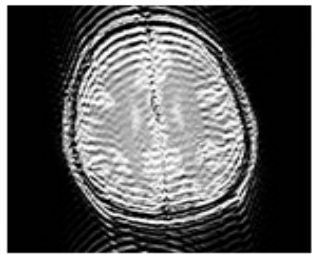

MRI

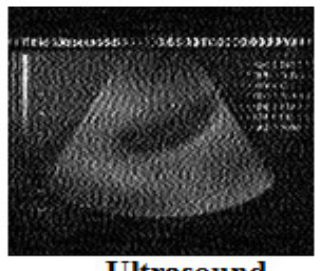

Ultrasound

Figure 8. Restored image of X-Ray Chest, CT, MRI and Ultrasound using Wiener Filter 


\section{Performance Parameters}

For performance parameters, various medical images were considered of different type and size 256 X 256. Performance Metrics are MSE (Mean Square Error) and PSNR (Peak Signal to Noise Ratio).

MSE: It is defined as the difference between the actual and the estimated signals . It is expressed as follows.

$$
\mathrm{MSE}=\frac{1}{\operatorname{mn}} \sum_{i=0}^{m-1} \sum_{j=0}^{n-1}\left[I(i-j)-K\left(i_{i} j\right)\right]^{2}
$$

Where I,K represent the original image and the restored images respectively of size mxn. An i,j represent the pixels of images.

PSNR: It is defined as the ratio between the maximum possible power of a signal and the power of computing noise that affects the fidelity of its representation. PSNR is expressed in terms of decibel $(\mathrm{dB})$. It is expressed mathematically as follows:

$$
\text { PSNR }=10 \cdot \log _{10}\left(\frac{M A X_{l}^{\mathrm{I}}}{M S E}\right)
$$

\section{EXPERIMENTAL RESUltS}

In this paper we have the iterative results in the form of deblurred image, PSNR and MSE values for Blind deconvolution algorithm. When we set the iterations to 50 in Table 1 for our experiment, we have the output image along with the PSNR value at maximum of $29.61852 \mathrm{~dB}$ and MSE+0.00109 dB for Weiner filter. Then as we increase the number of iterations to 70 as shown in Table 2, the PSNR value gradually decreases when compared to previous iterations at a maximum of $29.43213 \mathrm{~dB}$ and MSE $+0.00114 \mathrm{~dB}$ for Weiner filter. It can be represented graphically in the form of graph so that we can visualize it in an easy manner. The Figure 9. below shows the comparison of inverse filter and weiner filter for an iteration 50 .

Table 1. MSE \& PSNR Values of Medical Images of size 256 x 256 at an Iteration of 50

\begin{tabular}{|c|l|c|c|c|c|}
\hline \multirow{2}{*}{$\begin{array}{c}\text { S.N } \\
\text { o }\end{array}$} & \multirow{2}{*}{ Image } & \multicolumn{4}{|c|}{ Performance Measures } \\
\cline { 3 - 6 } & & \multicolumn{2}{|c|}{ Inverse Filter } & \multicolumn{2}{c|}{ Weiner Filter } \\
\cline { 3 - 6 } & $\begin{array}{c}\text { Mean Square } \\
\text { Error } \\
\text { (MSE) }\end{array}$ & $\begin{array}{c}\text { Peak Signal to } \\
\text { Noise Ratio }\end{array}$ & $\begin{array}{c}\text { Mean Square } \\
\text { Error } \\
\text { (MSE) }\end{array}$ & $\begin{array}{c}\text { Peak Signal to } \\
\text { Noise Ratio }\end{array}$ \\
\hline 1 & $\begin{array}{l}\text { X-Ray } \\
\text { Chest.png }\end{array}$ & $+0.01716 \mathrm{~dB}$ & $+17.65530 \mathrm{~dB}$ & $+0.00165 \mathrm{~dB}$ & $+27.82729 \mathrm{~dB}$ \\
\hline 2 & CT.jpg & $+0.00810 \mathrm{~dB}$ & $+20.91485 \mathrm{~dB}$ & $+0.00397 \mathrm{~dB}$ & $+24.00683 \mathrm{~dB}$ \\
\hline 3 & MRI.jpg & $+0.02057 \mathrm{~dB}$ & $+16.86871 \mathrm{~dB}$ & $+0.00109 \mathrm{~dB}$ & $+29.61852 \mathrm{~dB}$ \\
\hline 4 & $\begin{array}{l}\text { Ultrasound. } \\
\text { png }\end{array}$ & $+0.00750 \mathrm{~dB}$ & $+21.24827 \mathrm{~dB}$ & $+0.00403 \mathrm{~dB}$ & $+23.94484 \mathrm{~dB}$ \\
\hline
\end{tabular}


International Journal of Advanced Information Technology (IJAIT) Vol. 6, No. 1, February 2016

Table 2. MSE \& PSNR Values of Medical Images of size 256 × 256 at an Iteration of 70

\begin{tabular}{|c|c|c|c|c|c|}
\hline \multirow[b]{3}{*}{ S.No } & \multirow[b]{3}{*}{ Image } & \multicolumn{4}{|c|}{ Performance Measures } \\
\hline & & \multicolumn{2}{|c|}{ Inverse Filter } & \multicolumn{2}{|c|}{ Weiner Filter } \\
\hline & & $\begin{array}{c}\text { Mean Square } \\
\text { Error } \\
\text { (MSE) }\end{array}$ & $\begin{array}{c}\text { Peak Signal to } \\
\text { Noise Ratio }\end{array}$ & $\begin{array}{c}\text { Mean Square } \\
\text { Error } \\
\text { (MSE) }\end{array}$ & $\begin{array}{c}\text { Peak Signal } \\
\text { to Noise } \\
\text { Ratio }\end{array}$ \\
\hline 1 & $\begin{array}{l}\text { X-Ray } \\
\text { Chest.png }\end{array}$ & $+0.01744 \mathrm{~dB}$ & $+17.58538 \mathrm{~dB}$ & $+0.00170 \mathrm{~dB}$ & $\begin{array}{c}+27.69042 \\
\mathrm{~dB}\end{array}$ \\
\hline 2 & CT.jpg & $0.00810 \mathrm{~dB}$ & $+20.91277 \mathrm{~dB}$ & $+0.00406 \mathrm{~dB}$ & $\begin{array}{c}+23.91201 \\
\mathrm{~dB}\end{array}$ \\
\hline 3 & MRI.jpg & $+0.02089 \mathrm{~dB}$ & $+16.80152 \mathrm{~dB}$ & $+0.00114 \mathrm{~dB}$ & $\begin{array}{c}+29.43213 \\
\mathrm{~dB}\end{array}$ \\
\hline 4 & $\begin{array}{l}\text { Ultrasound.p } \\
\text { ng }\end{array}$ & $+0.00740 \mathrm{~dB}$ & $+21.30796 \mathrm{~dB}$ & $+0.00393 \mathrm{~dB}$ & $\begin{array}{c}+24.05538 \\
\mathrm{~dB}\end{array}$ \\
\hline
\end{tabular}

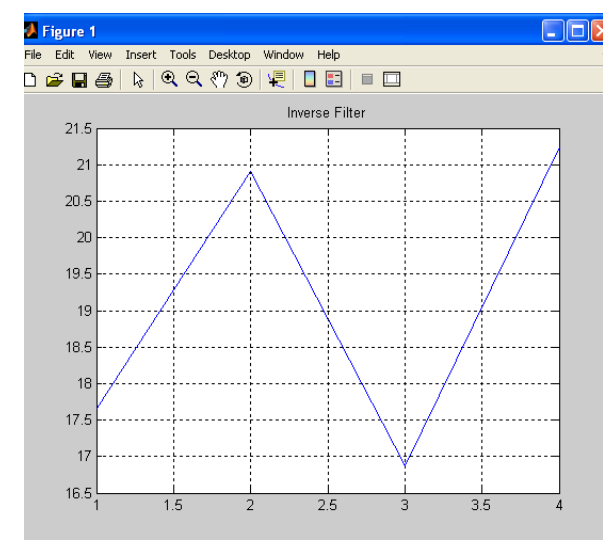

(a)

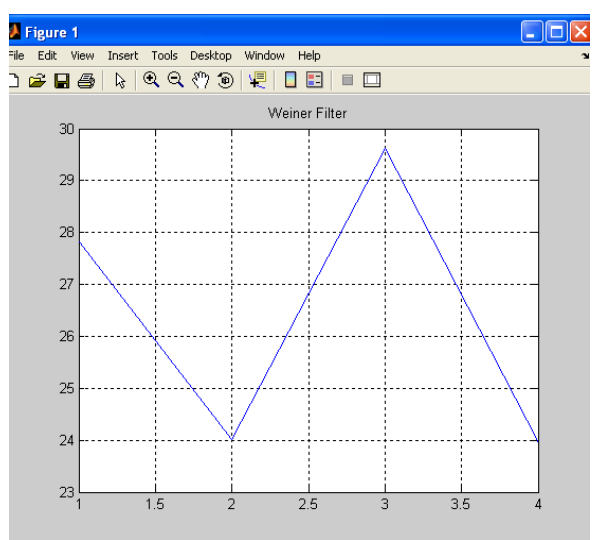

(b)

Figure 9. Comparison of Inverse filter and Weiner filter for an iteration 50.

\section{CONCLUSIONS AND Future WorK}

In this paper, we have studied a method for blind deconvolution algorithm. To conclude restoration of medical images like X-ray, CT, MRI and ultra-sound is very crucial and sensitive matter. The restoration must be done to maximum possible level. The PSNR value of Inverse filter is poor when compared with that of Weiner Filter. Future work of this paper is to develop and build improved technique which will give better performance than Weiner.

\section{REFERENCES}

[1] Charu Khare and Kapil Kumar Nagwanshi,'Image Restoration Technique with Non Linear Filter", International Journal of Advanced Science and Technology, Vol.39,pp. 67-74,February 2012.

[2] Rinku Kalotra , Sh.Anil Sagar,"A Review: A Novel Algorithm for Blurred Image Restoration in the field of Medical Imaging",International Journal of Advanced Research in Computer and Communication Engineering,Vol.3, Issue 6, June 2014. 
International Journal of Advanced Information Technology (IJAIT) Vol. 6, No. 1, February 2016

[3] Anamika Maurya, Rajinder Tiwari," A Novel Method of Image Restoration by using Different Types of Filtering Techniques", International Journal of Engineering Science and Innovative Technology(IJESIT), Vol 3, Issue 4, July 2014.

[4] Amandeep Kaur Vinay Chopra, "Blind Image Deconvolution Technique for Image Restoration Using Ant Colony Optimization,'International Journal of Computer Applications \& Information Technology Vol. 1, Issue 2, September 2012.

[5] Ramya, S.; Mercy Christial, T, "Restoration of blurred images using Blind Deconvolution Algorithm," IEEE, Emerging Trends in Electrical and Computer Technology (ICETECT), pp.496-499,2011.

[6] Anders Ahlen and Mikael Sternad,'Wiener Filter Design Using Polynomial Equations”, IEEE Transactions on Signal Processing,Vol.39,No.11, pp.2387-2399,November 1991.

[7] http://dip.sun.ac.za/ mfmaritz/DIP/DIPweb/ Wiki_Wiener_deconvolution.pdf.

[8] Sanchez MG, Vidal V, Verdu G, Mayo P,Rodenas F.,"Medical Image Restoration with different types of noise",IEEE Eng Med Biol Soc. Conference Proceedings 2012.

[9] P.Suganthi, Mrs.A.Gokila, Dr.K.Ramasamy,"Satellite Image Restoration Using Shearlet Transform",International Journal of Scientific \& Engineering Research, Vol.5,Issue 5, May-2014

\section{Author}

Dr.P.Sumitra. received her Ph.D Degree in Computer Science from Mother Teresa Women's University, Kodaikannal, Tamil Nadu, India in the year 2013. She is currently working as a Assistant Professor in Department of Computer Science, Vivekanandha College of Arts and Sciences for Women, Elayamapalayam, Tiruchengode, TamilNadu,India. She published 17 International Journal papers, 4 papers in International Conference and 10 papers in National Conferences. Her research areas include Image Processing, BioMetrics, Data Mining and Artificial Intelligence. She has 13 years 8 Months of teaching experience in self finance

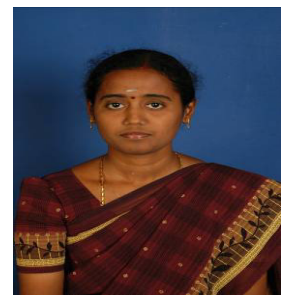
institutions. 